FERMILAB-TM-1975

\title{
Preliminary Report on the Utilization of the Fermilab Site for a Future Accelerator
}

The Site Utilization Working Group

Fermi National Accelerator Laboratory

P.O. Box 500, Batavia, Illinois 60510

October 1996 


\section{Disclaimer}

This report was prepared as an account of work sponsored by an agency of the United States Government. Neither the United States Government nor any agency thereof, nor any of their employees, makes any. warranty, express or implied, or assumes any legal liability or responsibility for the accuracy, completeness or usefulness of any information, apparatus, product or process disclosed, or represents that its use would not infringe privately owned rights. Reference herein to any specific commercial product, process or service by trade name, trademark, manufacturer or otherwise, does not necessarily constitute or imply its endorsement, recommendation or favoring by the United States Government or any agency thereof. The views and opinions of authors expressed herein do not necessarily state or reflect those of the United States Government or any agency thereof.

\section{Distribution}

Approved for public release: further dissemination unlimited. 


\title{
TM-1975
}

\section{Preliminary Report on the \\ Utilization of the Fermilab Site for a Future Accelerator}

\author{
July 8, 1996 \\ revised October 15, 1996
}

by

The Site Utilization Working Group 


\section{TABLE OF CONTENTS}

\section{EXECUTIVE SUMmaRY}

Chapter I: Methodology

C II: Illinois GEOlogy and Hydrology

ChAPTER III: UTILITIES

Chapter IV: LARge Hadron COLliders

Chapter V: Muon Colliders

Chapter VI: Electron Colliders

\section{REFERENCES}

Site Utilization Working Group
Don Cossairt
Larry Coulson
Helen Edwards
Dave Finley
Bill Fowler
Joe Lach
Ernest Malamud, Co-chair
Mike May
Bob Noble
Dave Neuffer
Stephen Pordes, Co-chair
Ray Stefanski




\section{EXECUTIVE SUMMARY}

- This report is a preliminary assessment of the utility of the Fermilab site for future accelerator projects. It responds to a request from the Director to evaluate how the Fermilab site and infrastructure may be relevant to future accelerator projects in the U.S.

- The report was prepared in time for distribution of a draft version at Snowmass 96, "New Directions for High-Energy Physics," June 25 - July 12, 1996.

- The SSC experience suggests that any major new project will have to be based on the existing infrastructure at one of the National Laboratories.

- This work presents only the technical issues and the benefits of the Fermilab site and infrastructure.

- The projects treated are:

- A really large hadron collider based on the "pipetron" vision of low-field ( 2 Tesla) magnets in a small diameter tunnel. Another option, not treated in detail, is a hadron collider using high field magnets.

- Muon Colliders with $250 \mathrm{GeV}$ and $2 \mathrm{TeV}$ per beam.

- A linear electron collider with 250 to $500 \mathrm{GeV}$ per beam.

- The infrastructure of the state of Illinois - geology, hydrology, power and surface water- seems remarkably well suited to any of these projects.

- The geology of most of Illinois, including Fermilab, contains a dolomite layer that:

- has low seismic activity.

- is at an appropriate depth to provide radiation protection.

- is essentially impervious to water movement and thus satisfies hydrology requirements.

- There is adequate electrical power - both locally and statewide.

- We first give brief overviews of the Fermilab and Illinois infrastructure - geology, hydrology, power, and water - and then a summary of each project.

- On the basis of what we have learned, we feel that Fermilab must be considered seriously as a site for any of these projects. Beyond this point, however site-specific plans will need to be developed for each of the projects. 


\section{Chapter I: Methodology}

- The Site Utilization Working Group established a list of items to address and as information was gathered it was reviewed in weekly meetings:

- Maps showing the Fermilab site boundaries, major roads, rivers, and candidate sites for the new accelerator.

- Geology issues.

- Hydrology issues especially as they relate to ground water activation.

- Which parts of the projects are arbitrary and which are intrinsic (e.g., relation between muon proton driver and muon collider rings).

- How existing accelerators at Fermilab are relevant to each project.

- How existing technology at Fermilab is relevant to each project.

- This is an ambitious list and the extent to which each accelerator project could address any of these topics depended on the state of the project.

- As a group, we concentrated initially on issues that would be common to all the projects siting, geography and geology, and power and water. We have been able to use some of the extensive geological work done in preparing the Illinois proposal for the SSC.

- All projects can benefit from Fermilab's outstanding engineering and technical facilities and the skill and experience of the staff.

- The NLC design has reached the ZDR stage under SLAC's leadership and TESLA is expected to reach a similar stage by the end of 1996 under DESY's leadership.

- Both the Muon Collider and a Large Hadron Collider can probably use portions of the present accelerator complex. Both of these projects are presently concentrating on establishing technical feasibility and baseline costs. Detailed strategies of how to use existing facilities are only now being developed. While both the Muon Collider and the low-field hadron collider ("pipetron") give such strategies here, it is almost certain that these plans will evolve over the next few months.

- We did not insist on the interaction region being on site but allow for the possibility of a "west" campus within an hour's drive.

- We wanted to minimize the impact on the general public in terms of siting, construction and operation.

- We assumed that most of the underground enclosures would be constructed by boring rather than trenching. 


\section{ChAPTER II: Illinois GeOlogy AND HydRology}

\section{Summary}

- Illinois geology is well suited to the construction of underground enclosures of the type needed for future accelerators.

- The thick layer of dolomite material over a large area is mechanically stable, suffers very low levels of vibration and has low seismic activity.

- This layer provides a well understood and monotonous tunneling environment.

- The dolomite is impervious to water thus minimizing construction problems due to infiltration and reducing ground water contamination problems.

\section{Geology of the Fermilab Region}

Crucial to future planning for accelerators connected with the Fermilab complex is an understanding of the Illinois geographical and geological setting. We start with a general description of the state wide geology and then focus on the closer Fermilab region.

The Illinois region consists of bedrock units overlain with glaciated materials. While the sedimentary bedrock units have a relatively simple pattern, the glacial surficial deposits reflect the complexity of the passage of many glacial epochs. It is important that the geological materials and their hydrogeologic properties be evaluated from the surface to a depth of several hundred feet. Primary factors to consider include:

- Thickness, distribution, and character of glacial and rock units, from the surface to a depth of about 600 feet.

- Stability of the earth's crust, including fractures and faults.

- Seismicity: the potential effects of earthquakes.

- Stability and strength of bedrock for tunnel considerations.

- Sufficiency of supplies and protection of groundwater resources.

Much of the material presented here comes from extensive studies done by the Illinois State Geological Survey, cited in Environmental Geology Note 111 (1985) [1] and references therein.

Figures 1-4 show the geology of the bedrock surface, surficial deposits, topography of the bedrock surface, and the thickness of the glacial material, respectively. In these figures, we see the distribution of the various deposits over the Illinois landscape. 


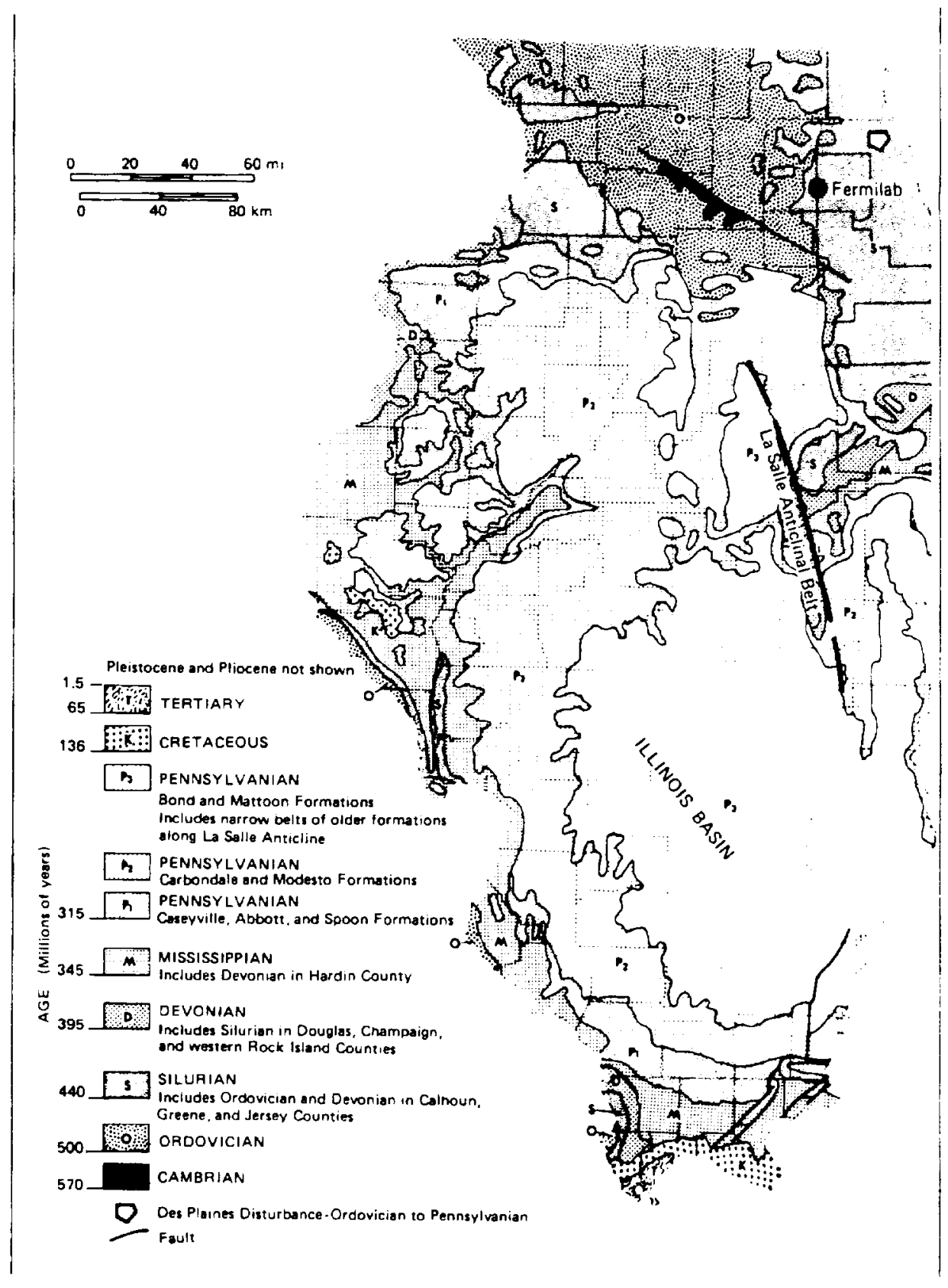

Figure 1. Geology of the bedrock surface. 


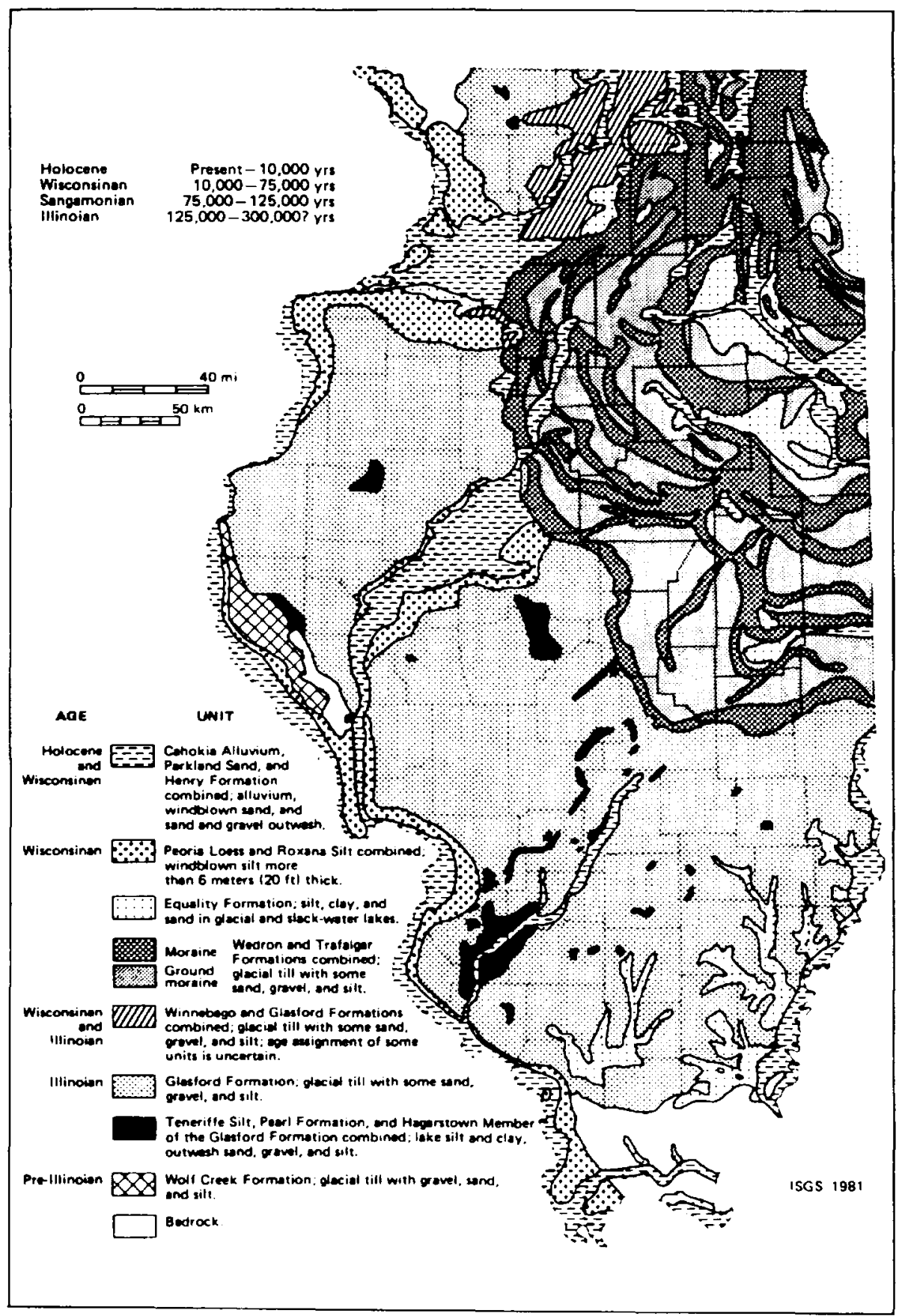

Figure 2. Geology of the surficial deposits. 


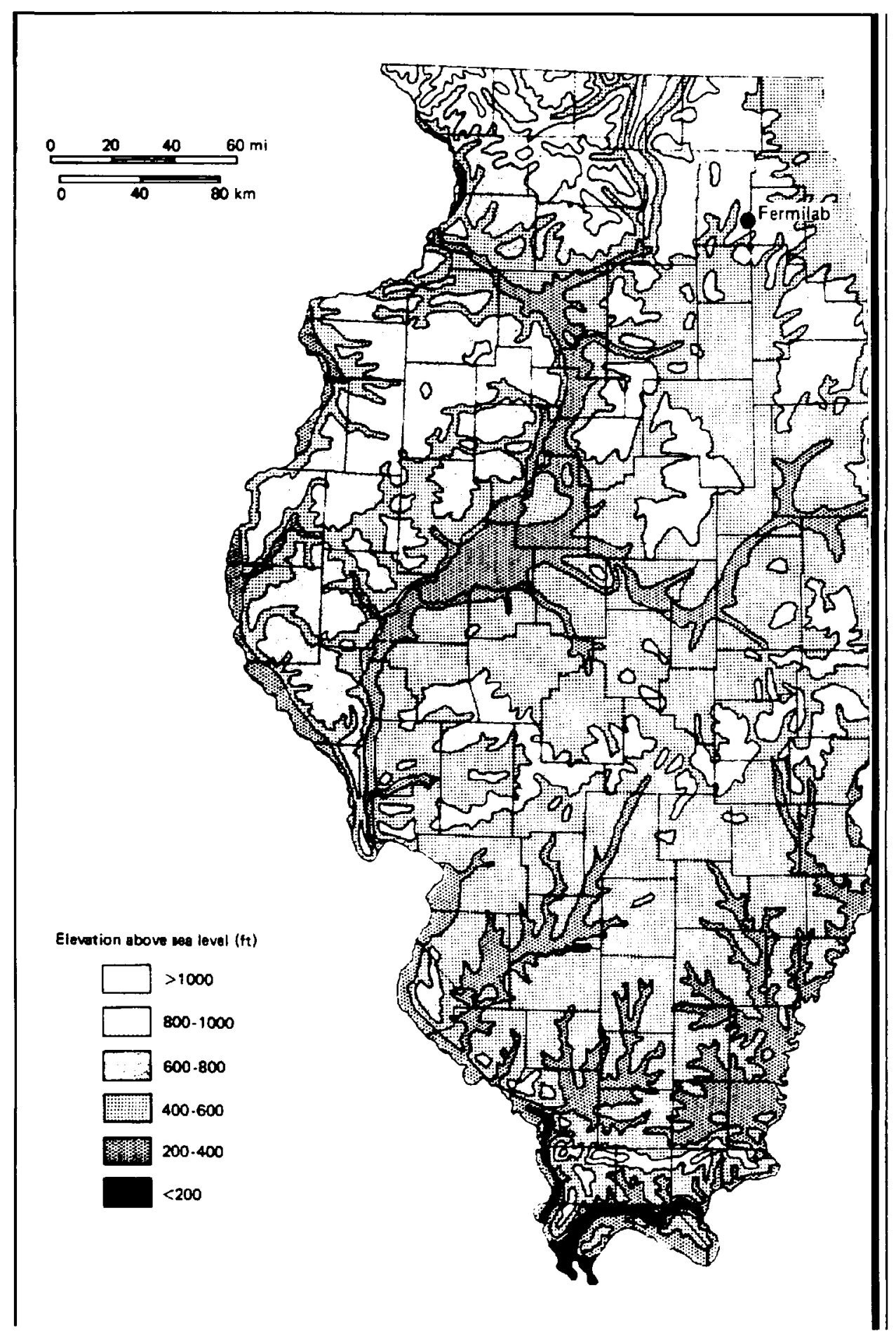

Figure 3. Topography of the bedrock surface. 


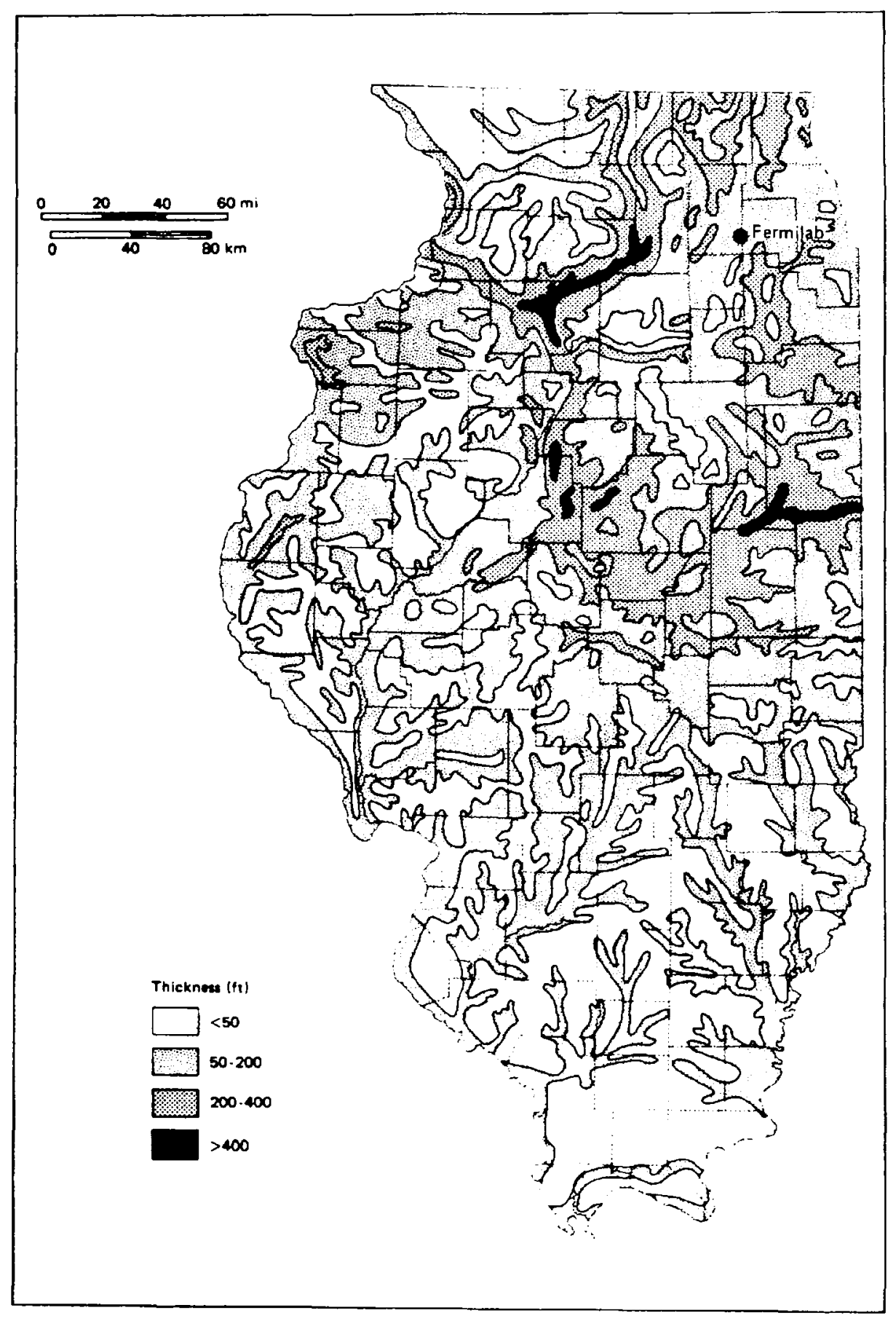

Figure 4. Thickness of the glacial material. 
The vertical distribution of materials can be separated into two categories, the bedrock units and the drift materials. The stratigraphic columns for these two categories are shown in Figs. 5 and 6, respectively. This set of figures represents an overview of the Illinois geology. For specific areas a much more detailed picture is available in Illinois State Geological Survey reports, computer data bases, and field surveys. Note that the bedrock units represent a relatively simple structure whereas the drift material distribution reflects the complex glaciation process that has occurred over this area.

Extensive tunneling that has been done in the Chicago area as part of a major water retention project, the Tunnel and Reservoir Project (TARP). This consists of nearly 100 miles of tunnel (some to about $10 \mathrm{~m}$ in diameter) and 266 shafts in Silurian dolomite rock. This material has predictable rock and tunneling conditions which is reflected in the well understood and documented costs of local tunneling.

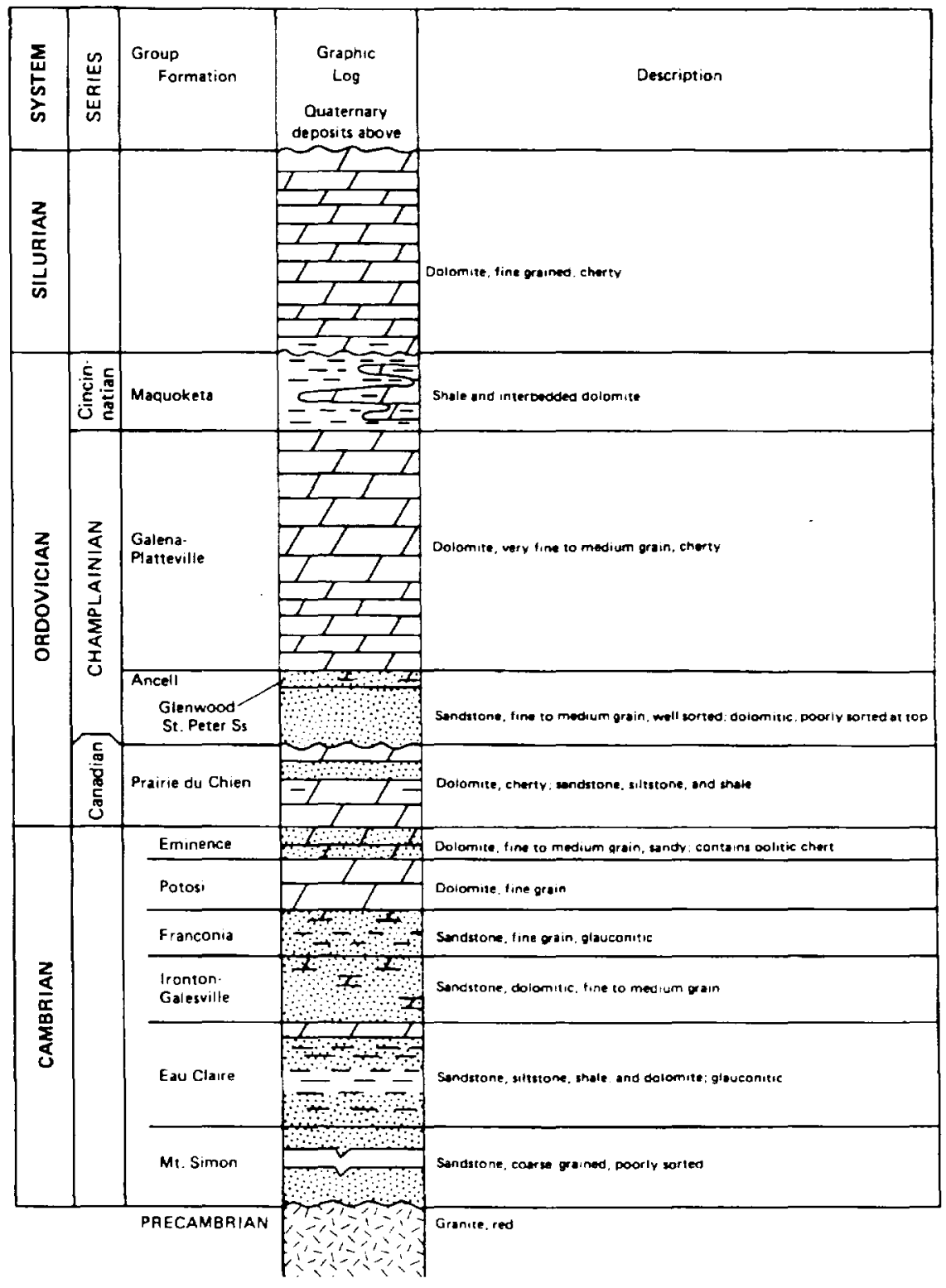

Figure 5. Stratigraphic column for the bedrock units. 


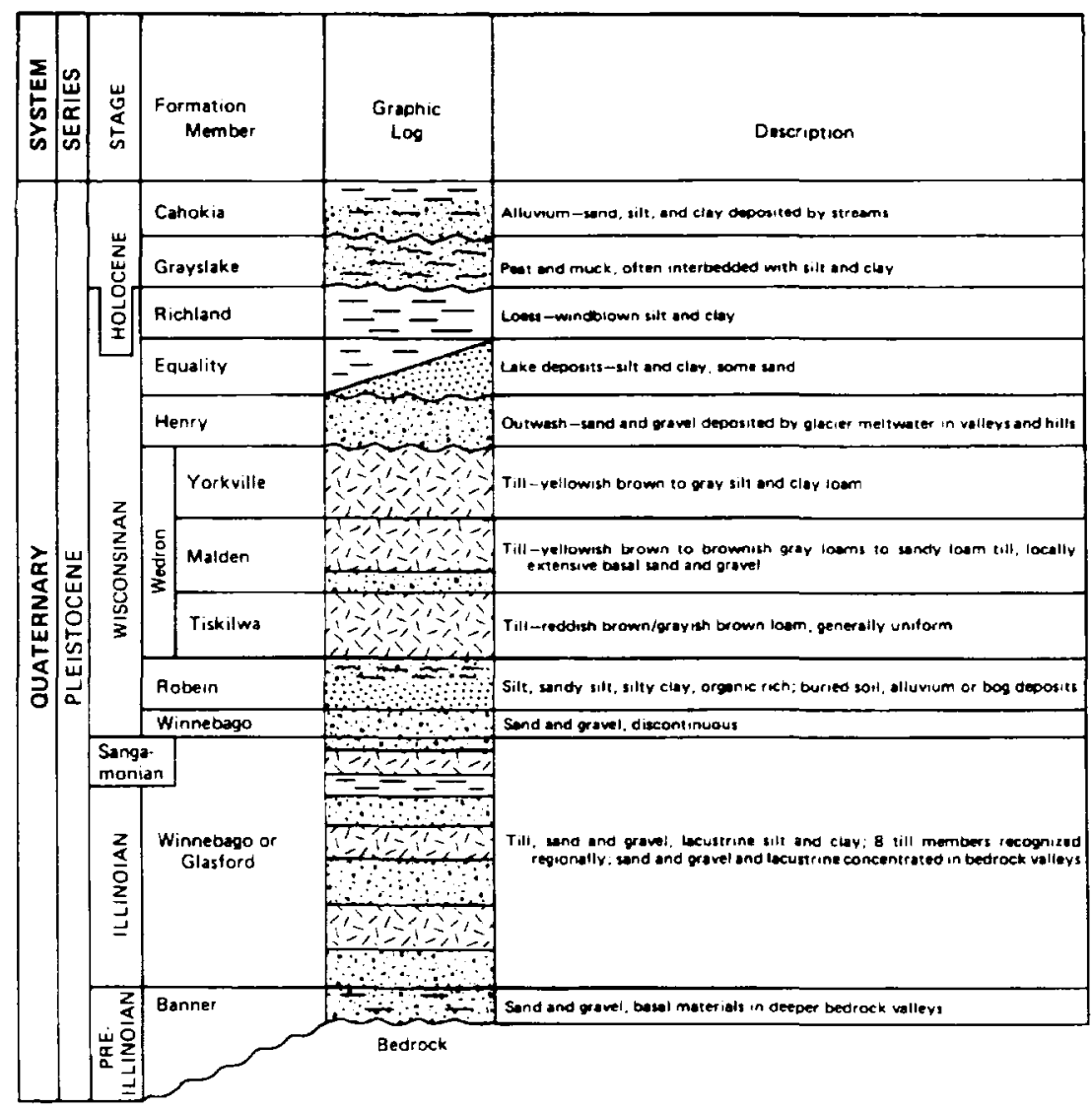

Figure 6. Stratigraphic column for the drift materials.

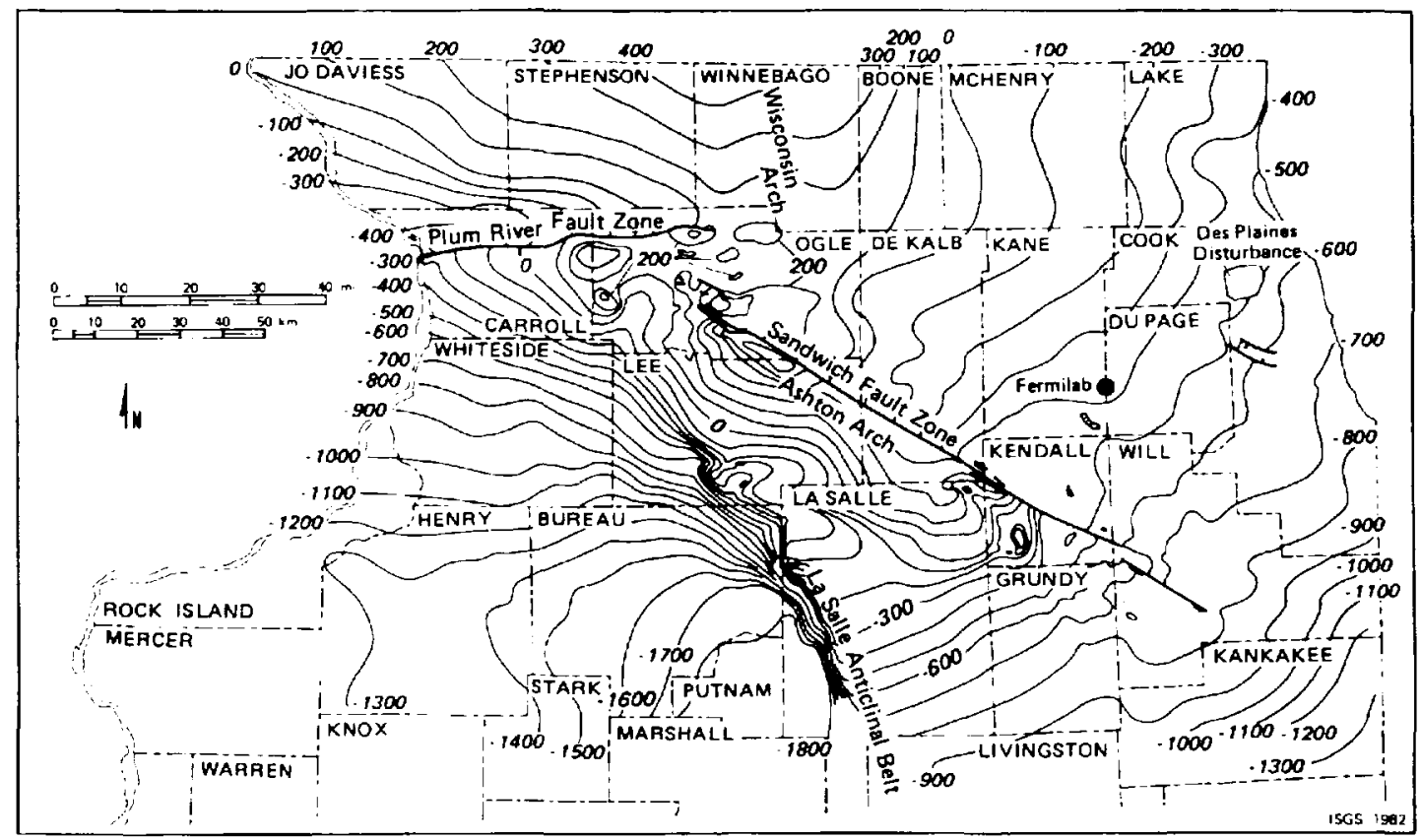

Figure 7. Top of the Franconia formation and local fault zones.

Figure 7 shows the top of the Franconia formation and some of the local fault zones. These are all inactive faults and have shown no activity in recorded history. Although attention must be given these fault regions in tunneling, they present no major construction obstacles. The northern Illinois region is a seismically stable, vibration free environment with no settlement problems. 
The northern Illinois region is one of low seismic activity and has experienced no significant earthquakes in recorded history. This is illustrated in Fig. 8 and Fig. 9 by the two maps showing the earthquake and volcanic risk over the continental United States (taken from the August 1985 issue of National Geographic magazine).

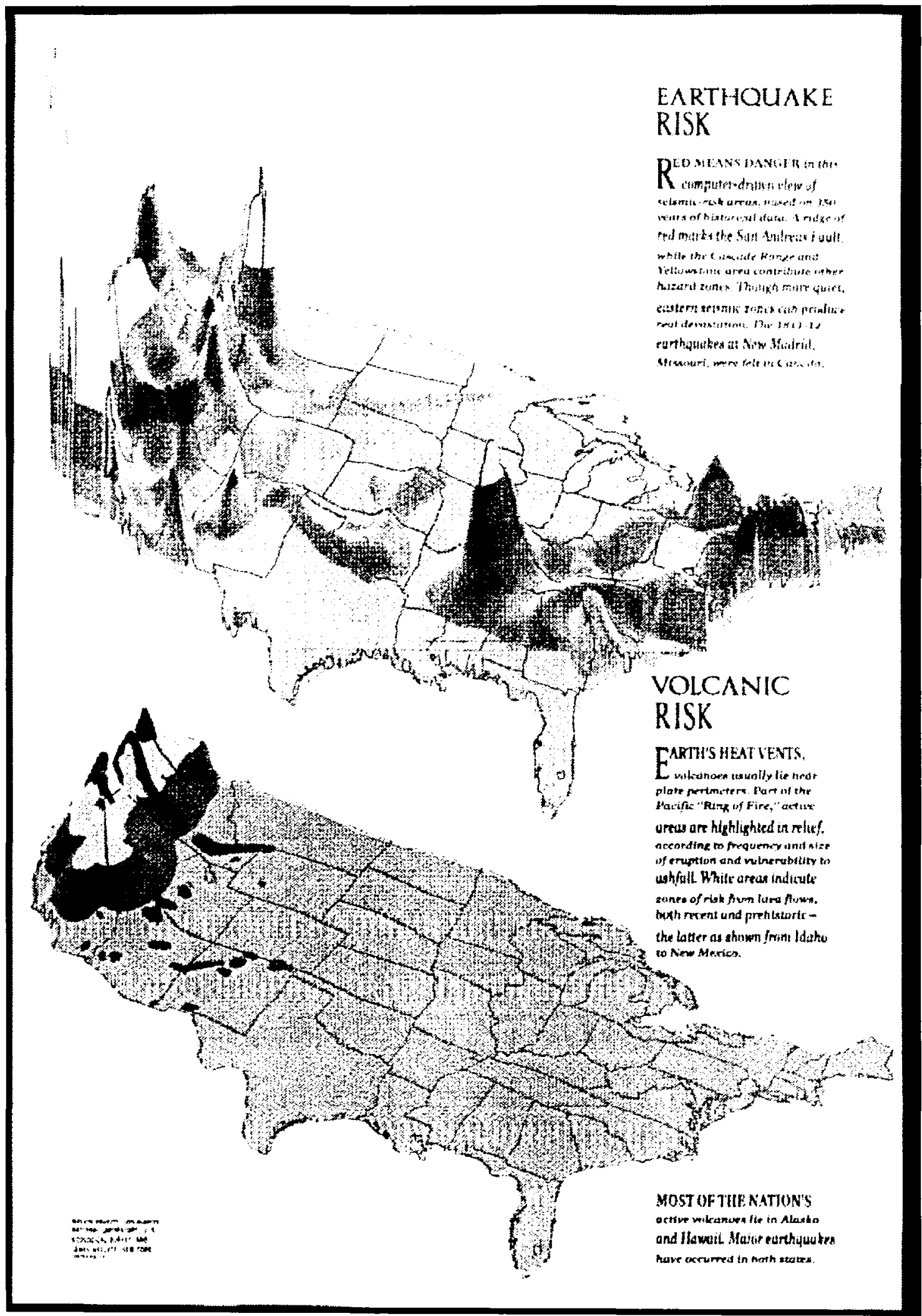

Figures $8 \& 9$ 


\section{Hydrology}

It is important to understand Illinois water resources and their relation to the geological setting. The major water supply for Chicago (and many of its suburbs) is Lake Michigan. This is an inexhaustible supply for the foreseeable future of soft (low mineral content) surface water used for domestic and industrial purposes. In other areas which do not have access to local surface water (rivers, lakes, etc.) water is pumped from wells. Low capacity private wells generally are drilled to the top of local bedrock. Municipal wells which require larger capacity are drilled to aquifers in sandstone deposits below the dolomite where accelerator tunnels would be located. The dolomite layers are aquatards and generally impervious to water. Thus many of the TARP tunnels which are in dolomite do not require linings to prevent infiltration of water.

The types of geological materials in northern Illinois that yield water in sufficient quantities to be a factor in construction of underground tunnels are:

- sand and gravel deposits within glacial drift

- the fractured and weathered surficial bedrock overlain with drift

- porous layers of bedrock - primarily the layers with a high content of sandstone.

The depth of the glacial drift varies from almost none to layers many hundreds of feet thick in ancient valleys. Distributed throughout the glacial drift are layers of sand or sandy clay which are sometimes extensive enough in area and depth to supply water for domestic use. In most places where drift overlays bedrock, the upper 50 or so feet of the surfical bedrock is weathered and will supply enough water for domestic use. In summary, the glacial drift and top of the surfical bedrock form a unit that supplies many domestic wells throughout the area. Since accelerator construction would not be in these materials, no difficulty is anticipated.

The upper most bedrock unit underlying the area that is used as a reliable source of water for community supplies is the Ancell (Glenwood-St. Peter sandstone) which lies directly under the Galena-Platteville dolomite layer (Fig. 5). Just below is the Prairie du Chien which is an important aquifer especially in the southern part of the area. The major unit used throughout the area for large supplies of water is the Ironton-Galesville sandstone. This unit is very deep in the eastern area (over 1000 feet). The deepest geological unit used as an aquifer is the Mt. Simon sandstone. Accelerator construction would be above these layers so no difficulty is anticipated. 


\section{CHAPTER III: UTILITIES}

\section{Summary}

- There is ample available electric power in Illinois for a future accelerator at Fermilab.

- Expansion of the cooling pond system on site may be required for the lepton colliders.

\section{Electricity}

The projects considered have different power requirements. The electron and muon colliders are estimated to require 200 - 300 Megawatts, while a low-field large hadron collider using a liquid helium cooling system requires less than 75 Megawatts. If either a low-field or high-field hadron collider is built using high temperature superconductors the power required is significantly lower.

The utility requirements for the three proposals under study can easily be met by the resources already in place or by expansion that would efficiently accommodate the new demands. The detailed study carried out by the State of Illinois for the SSC site in Illinois documents many aspects that are similar to considerations for other future facilities such as the three in this report. For example, Commonwealth Edison examined their electric power system in order to assess its ability to accommodate the estimated 200 megawatt load of the SSC. Since Commonwealth Edison has one of the largest electric generating systems in the country, there was no difficulty in incorporating the 200 megawatt estimated load into the projections of future load and margin requirements. Peak load in 1995 was 18,600 Megawatts with a reserve margin of $18.6 \%$.

Using up to 300 Megawatts as the estimated electric power requirement for any future project such as a lepton collider at Fermilab with a startup date of $\sim 2010$, one finds in comparison the estimated peak load for the Commonwealth Edison system to be 24,300 Megawatts. Therefore, $\sim 1.2 \%$ compared with the currently planned reserve margin of $18 \%$ would be used up by the new Fermilab load; however, as better data is accumulated on the growth of demand, Commonwealth Edison would decide on whether it might be desirable to add new generating capacity or increase the use of the 28 interconnects that it has to nine other utilities. The company policy is to maintain a target reserve capacity of $15 \%$ and uses an annual growth rate of $2 \%$. There is no question that ample and stable electric power is available for a new high energy physics project at Fermilab.

One particularly interesting possibility would be to have the electric power for the new load serviced by the two $345 \mathrm{kV}$ transmission line connections at Fermilab, with underground distribution within the accelerator tunnel. The line capacity for the new $345 \mathrm{kV}$ line under construction for the Main Injector has a capacity of over 900 Megawatts. It is obvious that a combination of the original $345 \mathrm{kV}$ line and the new Main Injector line easily accommodates a new 300 Megawatt electric power demand. Additional transformers would be required in the substation yards. By using this scheme one would avoid the public's sensitivity to new electric power lines.

\section{Surface Water and Cooling}

From the early days of Fermilab, the founding Director, Robert R. Wilson, was diligent in seeing that the Laboratory minimized the impact of operations on the local surface waters and groundwater resources, even though northeastern Illinois had an abundance of water. During the design of 
Fermilab, the architects and engineers evaluated the available water sources in terms of economics, quality, and reliability. For the industrial cooling water, a cooling pond system was developed which would use for make-up rainfall collected on the 6,800 acre site, and for back-up during dry, hot periods water from the Fox River and, if necessary, under unusual circumstances, from wells. Before the commissioning of the superconducting Tevatron when the Main Ring was operated up to $400 \mathrm{GeV}$ with electrical loads of 80 Megawatts, the magnets were successfully cooled by this system. Currently the maximum load is during fixed-target operation at a level of $\sim 60$ Megawatts.

The current cooling pond system, including the new Main Injector ponds now under construction, has an average summer evaporation rate of about $60,000 \mathrm{GPH}$ with reservoir capacity to support an 82 day design drought. During non-drought conditions, make-up water is derived primarily from storm water run-off, with supplemental supply pumped from the Fox River. Well water has never been required.

The breakdown of pond groups and their maximum non-simultaneous loads once the Main Injector comes on line, is a follows:

\begin{tabular}{|c|c|c|c|}
\hline $\begin{array}{r}\text { Surface } \\
\text { Pond Group } \\
\end{array}$ & Acreage & $\begin{array}{c}\text { Max. } 1 \\
\text { Load } \\
\end{array}$ & Acres/MW \\
\hline Main Ring Ponds & 27.0 & 15.6 & 1.7 \\
\hline Main Injector Ponds & 19.0 & 21.9 & 0.9 \\
\hline CUB Ponds (Swan Booster, etc.) & 10.7 & 15.9 & 0.7 \\
\hline Main Ring Lake & 42.1 & 4.0 & 10.5 \\
\hline Casey \& New Pond & 18.0 & 14.0 & 1.3 \\
\hline Bullrush Pond & 1.6 & 0.7 & 2.3 \\
\hline Law Lake & 45.1 & 0.0 & N/A \\
\hline AE SEA & 49.6 & 0.0 & N/A \\
\hline DUSAF Pond & $\underline{16.6}$ & $\underline{0.0}$ & $\underline{N} / \mathrm{A}$ \\
\hline Total Site & 229.7 & 72.1 & $\mathrm{~N} / \mathrm{A}$ \\
\hline
\end{tabular}

From the above, it can be seen that the normal acre/MW requirement for ponds which cool year round, ranges from 0.9 (Main Injector), to 1.3 (Casey and New Pond), depending upon the efficiency of design achievable. The high acre/MW ponds in the list (Main Ring, MR Lake, and Bullrush) are not fully loaded, and the low acre/MW ponds (CUB), do not perform cooling during the summer.

For facilities where the new heat loads would be concentrated on the Fermilab site; i.e., the muon collider or the electron collider centered on Fermilab, the industrial cooling water system would need to accommodate an approximately fivefold increase.

Loading the existing 229.7 acres of site ponds to $300 \mathrm{MW}$ would yield an average of 0.8 acre/MW. This would result in approximately $5^{\circ} \mathrm{F}$ higher water temperatures than normal and the use of specially designed cooling equipment would be required. Using conventional design parameters, you would normally expect between 270 and 390 acres of cooling pond surface.

Evaporation rates will range between 190,000 and $250,000 \mathrm{GPH}$ with the lower figure applicable to hotter, smaller ponds which use a larger convective cooling component. This would argue that 
the present site reservoir capacity of 370 acre-feet will have to be expanded by 800 to 1100 additional acre-feet to maintain an 82 day drought reserve.

Looking at three different scenarios, the additional reservoir capacity can be developed by dredging Main Ring Lake, Lake Law, and the AE SEA for an additional 5 foot freeboard (if we decide to stay with the approximate 230 acres), or by designing a 20 foot freeboard in a new 40 acre pond (if we decide to expand to 270 acres), or by designing a 5 foot freeboard in a new 160 acre pond (if we decide to expand to 390 acres).

Total annual make-up water requirements would range between 3,000 and 4,000 acre-feet. The average annual precipitation on site is roughly 20,000 acre-feet and as much as possible would be impounded for this purpose. In addition to this, we currently take in 750 acre-feet annually from the Fox River on average, with a maximum present capacity of 1,500 acre-feet (provided river flow is adequate for usage).

As more information is developed it will be possible to optimize designs and determine the most suitable expansion of the cooling pond system.

\section{Site Utility Easements}

Gas and electricity utilities border the site as shown below. Accelerator structures would be much deeper than these utility easements so would not interfere. However, care must be taken in siting surface buildings and accesses.

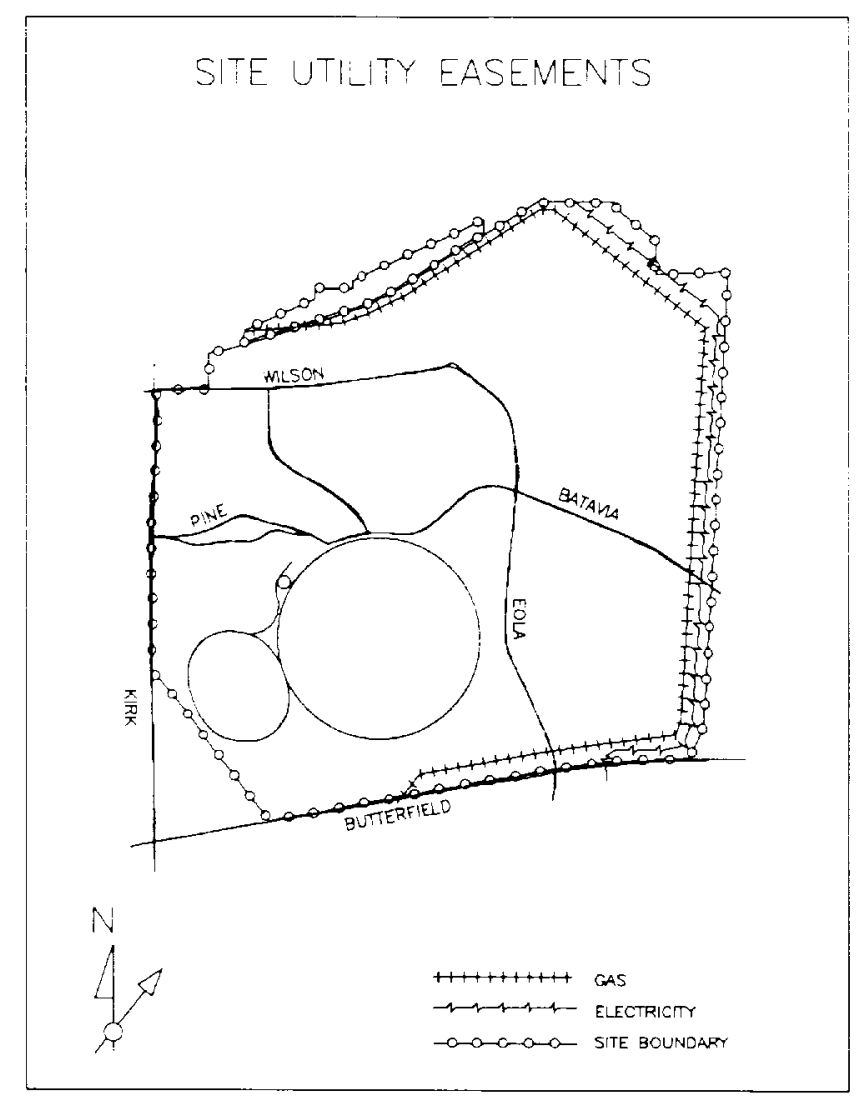




\section{$\underline{\text { Radiation Safety Issues }}$}

The various accelerator projects envisioned can furnish very little of the design detail that is necessary to provide a full consideration of the radiation safety implications. However, even at this early stage, it is clear there will be issues related to radiation protection of the employees, environment, and the public. Based on the past success of large accelerator projects in dealing with these issues and extrapolating what we know to these higher energies, we can be confident that any of these projects could be built here in full compliance with all applicable radiation protection standards. The skills in calculating quantities and locations of shielding to provide this protection are very well understood.

Generally protection of the employees will be addressed by measures which have been developed and have been used successfully for many years at Fermilab. None of the proposed projects pose any unique or even significantly different issues than those handled routinely at Fermilab.

Radiation protection considerations of the environment and public generally center on two issues-ground water protection and high energy muons. Protection of the ground water requires knowledge of the amount and distribution of radioactivity produced as well as location and movement of ground water. Fermilab has about 25 years of successful experience in designing groundwater protection features for its existing facilities. It has developed a reservoir of expert knowledge in predictive computer modeling techniques which calculate the amount and distribution of each isotope which can be produced for a given beam, beam energy and geometry of shielding. Many measurements have been made to verify the accuracy of the models. Fermilab has considerable knowledge of local groundwater locations and movements.

All of the proposed projects will produce and/or use high energy muons. Two characteristics of high energy muon production at a high energy accelerator contribute to the design features of a high energy accelerator facility. Muons have a long range through shielding material such as soil or rock and they are produced in a very narrow cone in the direction of the beam. Therefore, although a long distance is needed to attenuate a muon beam, up to a $\mathrm{km}$ or more of soil or rock, a cylinder with a rather narrow radius, usually a few meters is sufficient to contain them until they stop and decay into electrons. Most of the proposed designs involve situations in which the required attenuation cylinder will extend off the Fermilab site. In some cases the cylinder may be all or mostly off-site. However, since the beams are so narrow the simple technique of putting the accelerator tunnels deep underground will preclude exposure to the public. 


\section{CHAPTER IV: LARGE HADRON COLLIDERS}

\section{Summary}

- A very high energy hadron collider can advance the energy frontier by a large factor. This collider can be built either with high field or low field bending magnets.

- This chapter describes some of the details of a proposal for $\mathrm{a} \geq 50 \mathrm{TeV} x \geq 50 \mathrm{TeV} p$ collider $(\mathrm{Ecm}=\geq 100 \mathrm{TeV})$ using superferric magnets in a small diameter pipe, the low field approach. This proposed project is referred to as the "pipetron."

- The pipetron aims at one-tenth the cost per TeV of previous machines (LHC/SSC).

- The geology and hydrology of Illinois and surrounding region is well suited to such a large scale machine.

\section{Historical Note}

The concept of building an accelerator in a "sewer pipe" was clearly presented by Fermilab's Founding Director, R. R. Wilson at the Snowmass Conference in 1982. ${ }^{1}$

"Whether the next large proton accelerator (20 TeV?) is built on a national basis or as an international effort, to be affordable, innovations in construction must be made. The design of a superferric magnet ring buried in a pipe in the ground is explored here to see what reductions in cost might result."

"...superferric magnets (an old idea) have the advantage of simplicity, of being more sparing in the use of superconductor, less sensitive to the position of the superconductor, easier to construct, and perhaps more reliable to use."

Relevant technologies have emerged and grown rapidly since Snowmass 1982. Extrapolations of these technologies can bring this dream to reality in the next $10-20$ years.

\section{Project Goals and Assumptions}

- Define a path to $\geq 50 \mathrm{TeV}$ per beam ( $\geq 100 \mathrm{TeV}$ in the center-of-mass). The dipole magnet is a one-turn, superferric design, operating at $2.0 T$. With a combined function lattice a packing factor of $>90 \%$ is possible. Thus the circumference is $\geq 500 \mathrm{~km}$.

- Achieve as low a cost per TeV as possible. This cost includes the collider enclosure.

- Have as few surface accesses as possible, desirable to minimize impact on the public as well as to reduce costs.

- Accelerator is deep underground. Installation and maintenance work is largely with robots. Human access is made to rectify unusual problems, e.g. breakdown of the robots.

- This proposal is site-specific using the Fermilab Main Injector or Tevatron as the injector. It is highly desirable that the project be international in all phases: concept development, design, prototyping, construction, project management, and exploitation for physics. 
- It is important to keep in mind that there is an entirely different approach to a very high energy hadron collider: make the magnetic field as high as possible. ${ }^{2}$ It is important to make a careful comparison of the cost/ $\mathrm{TeV}$ of these two approaches.

Additional information is available in print 3,4 and on the web. ${ }^{5}$

\section{Rationale}

New approaches are required to continue the dramatic exponential rise in collider energies as represented by the well-known Livingston plot. The old idea of low-cost, low-field iron dominated magnets in a small diameter pipe may become feasible in the next decade with dramatic recent advances in technology:

- Advanced tunneling technologies for small diameter, non human accessible tunnels.

- Accurate remote guidance systems for tunnel survey and boring machine steering.

- High $\mathrm{T}_{\mathrm{c}}$-superconductors operating at liquid $\mathrm{N}_{2}$ or liquid $\mathrm{H}_{2}$ temperatures.

- Industrial applications of robotics and remote manipulation.

- Digitally multiplexed electronics to minimize cables.

- Achievement of high luminosities in p-p and proton-antiproton colliders.

There is an opportunity for mutually beneficial partnerships between Fermilab and the commercial sector to develop some of the necessary technology. This will gain public support for this undertaking, a necessary part of the challenge of building a new, very high energy collider.

\section{Why Fermilab?}

There are many reasons why Fermilab is the ideal site for the next large accelerator project in the United States. Specifically, for a hadron collider, one will make use of the existing accelerator complex for the injector, rather than repeating the error of attempting to reproduce that multi-billion dollar investment at a new green field site.

\section{Accelerator and Instability Issues}

There are accelerator dynamics issues that need to be addressed in considering this very high energy, and low revolution frequency collider.

One of the potentially most serious issues is emittance growth driven by noise. This noise spectrum rises logarithmically as the frequency becomes lower. There are two approaches to this problem; both must be investigated:

- Passive suppression by mechanically mounting the magnets to isolate them from sources of rapid motion and/or cryogenic/electrical system design eliminating sources of noise.

- Active suppression using feedback. This requires extremely low noise pickups and preamplifiers and damping times that are short compared to the nonlinearity induced decoherence times.

Clearly a site having low seismic activity, such as the Fermilab region, is an essential requirement.

\section{Siting the Pipetron or a High-field hadron collider in the Fermilab Region}

The geology in the Fermilab region is exceptionally well documented. The Silurian dolomite under Chicago and the dolomite under Fermilab are superb hosts for tunnels or drill holes 


\section{Site conditions at Fermilab}

The overall geology and hydrology of the Fermilab region have been described in chapter II. The pipetron benefits from the excellent conditions which provide for

- Well understood, predictable rock and tunneling conditions.

- Relatively homogenous rock mass.

- High seismic stability; no movement in recorded history.

- Vibration free environment

- $\quad$ No settlement problems.

Data comes from several hundred-thousand drill holes, and additional data compiled when there was active consideration given to siting the SSC in Illinois. Neighboring midwest states have similar extensive detailed information relevant to a large project of this sort.

\section{Ground Water}

In a glaciated region, groundwater is typically present in the glacial drift and in the uppermost few meters of bedrock. In the bedrock beneath Fermilab, the rate of movement of groundwater varies by three orders of magnitude.

The dolomite of the Galena-Platteville does not yield much water (water moves at only $1 \mathrm{ft} /$ year). Therefore, the dolomite is the attractive host for a tunnel or horizontal drill hole for an accelerator project. Major tunnels under the cities of Milwaukee and Chicago, constructed in the dolomite, have such low seepage rates that they are unlined.

\section{Building the Accelerator Enclosure}

Trenchless Technology is rapidly growing in importance as a practical solution to expansion and repair of underground utilities. This is the area where not only can a future accelerator project benefit from this technology as its capabilities expand but can also be a catalyst to this environmentally crucial industry. Iseley 6 describes its importance:

"Our nation's underground utility infrastructure is a valuable asset and a critical element in our global economic competitiveness. Practical solutions must be found to expand and rehabilitate that asset. Environmental concerns, combined with community relations, safety and the cost of utility services have created demand for new ways to expand and rehabilitate underground utility services."

Two approaches being considered: Microtunneling and Horizontal Directional Drilling. These technologies also have application to the other projects described in Chapters V and VI.

\section{Features of Microtunneling}

- A trenchless technology for constructing pipelines to very close $( \pm 1$ in.) tolerances.

- Remotely controlled, laser guided, system in which personnel entry is not required.

- Has historically referred to construction of tunnels of non man-sized inside diameter. The technique can, however, be used to install pipe of virtually any diameter.

- Has been used to install pipelines in a single pass operation in lengths up to $2,000 \mathrm{ft}$.

- Can be used in a variety of ground conditions from soft clay to rock. 
- Most microtunnels have been straight. Microtunnels that go in curves and follow terrain (as our large collider will do) are just beginning to be built, mostly in Europe.

- The first microtunnel in the U.S. was done in 1984. Atalah and Hadala ${ }^{7}$ have compiled the cumulative installed microtunneling in North America (in kilometers) of all types with projections for 1996 and 1997; the total is $200 \mathrm{~km}$.

\section{Standard tunnel boring and "enhanced" microtunneling}

If one compares "standard" tunnel boring (human access) and microtunneling (non-human access) one learns that the minimum in cost/foot vs. tunnel diameter today is $\$ 900 /$ foot for a $14 \mathrm{ft}$ diameter tunnel. These two technologies are merging into "enhanced microtunneling." Vigorous R\& will in the next few years move this minimum to a smaller diameter and lower cost/foot Development is towards better cutters to achieve higher production rates, longer distances between shafts, and improved muck removal methods. An achievable goal, given the excellent properties of Illinois dolomite for tunneling is to move the minimum to $\$ 300 /$ foot for an $8 \mathrm{ft}$ diameter tunnel.

\section{Features of Directional Drilling}

- Is a U.S. invention developed primarily for oil and gas exploration, in contrast to microtunneling where until recently advances have come mainly from Europe and Japan.

- Generally goes down from the surface at $45^{\circ}$, and then back up. Uses a fluid-driven motor mounted downhole directly above the bit. Can drill through rock at high speed.

- Usual technique is to drill a 10-12 in. diam pilot hole and then back ream from it and enlarge the hole. Diameters up to 48 inches are being done.

- The cost of horizontal drilling continues to drop.

- The biggest problem with horizontal drilling is the accuracy. Density variations in the rock cause the drill to veer from the desired direction.

\section{Robotics and remote manipulation}

Robotics (more correctly remote handling) are now being used for repair of sewer pipes ranging from 8 to $30 \mathrm{inch}$ in diameter with access every 300 - $400 \mathrm{ft}$ via manhole. The robots cut holes, put in patches, cut roots out, install new lateral connections, etc. Machines for pipe repair have been developed at Fermilab. ${ }^{8}$ This is a rapidly expanding industry. Visual reality is beginning to be used. Besides its application to the pipetron this technology may also be useful in improving the efficiency and lowering the cost of the accelerators considered in Chapters V and VI.

\section{Surface Penetrations}

An initial look at cryogenics and power supply/quench protection requirements are that an access shaft and surface building will be required every $80 \mathrm{~km}$ around the ring. Depending on evolution of the tunneling/boring industries and detailed cost optimization not yet done, additional accesses to the surface may be required. Clearly the fewer of these the better. Some of these additional access shafts may not need human access, but would be bore holes for surveying, or running cables of various kinds down to the enclosure.

\section{The Path to $>100 \mathrm{TeV}$ in the Center-of-Mass}

The choice of a path to the "ultimate" collider is based on

- Physics including complementarity with other projects, in particular LHC.

- Accelerator considerations, dynamic range in the magnet, and filling times. 
Site-fillers ( $15 \mathrm{~km}$ maximum circumference) have been considered for many years. A site-filler can serve as an injector into a higher energy ring, but more importantly would test out all the new approaches in the pipetron concept in an operating collider.

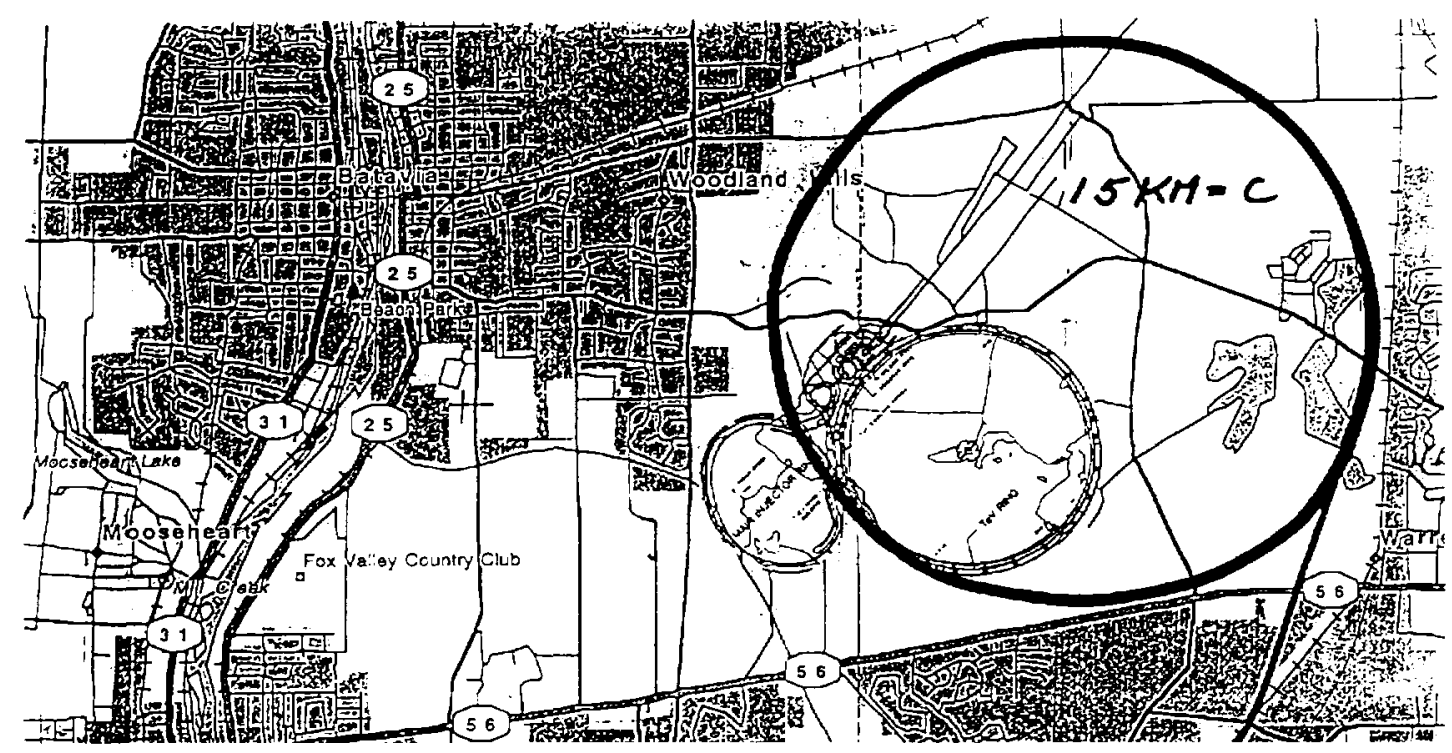

Figure 1. Site filler.

Figure 1 shows one possible layout for a site filler, where injection is from the Tevatron. An alternative, which results in faster filling time is to use the Main Injector. In this configuration, using 2.0 T, a maximum energy of $\sim 1.5 \mathrm{TeV} /$ beam is possible. This energy is probably too low to serve as a high energy Booster and inject into a $50 \mathrm{TeV}$ ring.

A larger ring, e.g. $3 \mathrm{TeV}, 30 \mathrm{~km}$, will be partly on the existing site and partly go beyond its boundaries. It is important for this ring to pass through the site so all of the functions requiring human intervention, including the detector use existing Fermilab infrastructure.

It should be possible to build this ring with few or even no off-site surface access points. It will serve as an injector and into the $\geq 50 \mathrm{TeV}$ "ultimate" pipetron. Also we will learn how to gain public acceptance of having a "proton pipeline" going under private property. We will learn from this process how to obtain underground easements. It is an important phase in the construction of the very large ring, for gaining experience with the new technologies and approaches. 


\section{Chapter V: MuON Colliders}

\section{Summary}

- A machine to collide muons at energies up to $4 \mathrm{TeV}$ is under study.

- Such a machine could be built within the Fermilab site.

- A demonstration machine, capable of producing top quarks, is a first step.

- The Fermilab site and accompanying infrastructure are ideally suited to the development of a muon collider.

\section{Introduction}

One possible path for the extension of particle physics capabilities to ultrahigh energies is the construction and operation of a $\mu^{+}-\mu^{-}$collider. Why build muon colliders?

- can reach much higher energy than $\mathrm{e}^{+} \mathrm{e}^{-}$due to much reduced synchrotron radiation.

- better energy definition of the initial state; $\Delta \mathrm{E} / \mathrm{E} \simeq 0.01 \%$

- for couplings proportional to the mass, e.g. s-channel $\mathrm{H}$ production, $\mu / \mathrm{e} \sim(207)^{2}$

- for some physics, "reach" is $10 x$ that of a hadron collider of the same cm energy.

\section{A $2+2 \mathrm{TeV} \mu \mu$ Collider}
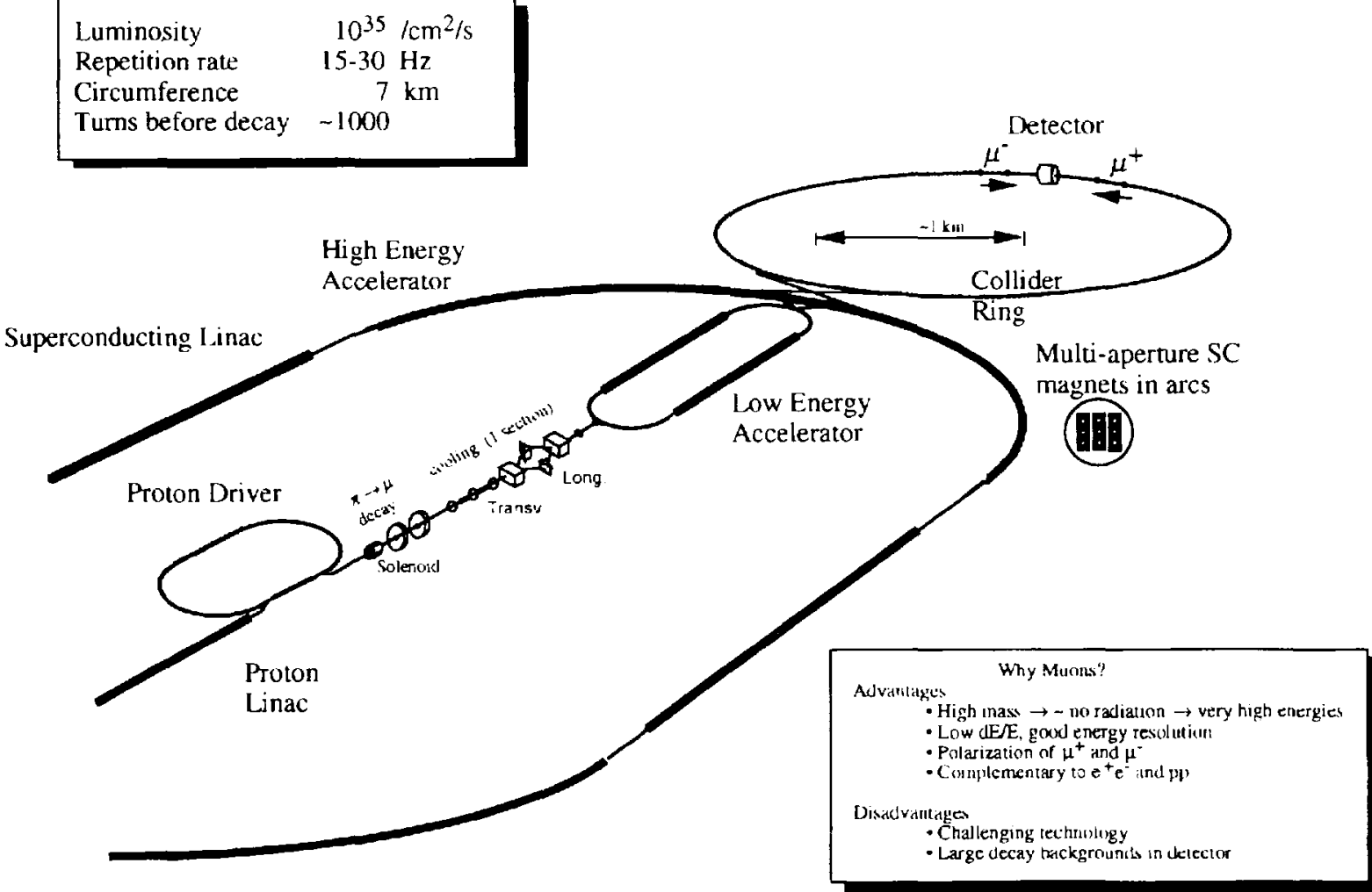
Recently considerable progress has been made toward developing the $\mu^{+}-\mu^{-}$collider concept. [1] Continued study and development along these lines could lead to a buildable collider design in $\sim 10$ years.

Technical problems from muon decay:

- need to accelerate them $\underline{\text { fast; }}$ at $2 \mathrm{TeV}, \tau=0.044$ seconds

- heat magnets of the collider ring

- create background in the detector

- created from $\pi$ decay into a diffuse phase space so stochastic or radiation cooling too slow; requires ionization cooling

Parameter lists for possible $\mu^{+}-\mu^{-}$colliders are shown in Table 1 , which includes the primary high-energy objective of a $4 \mathrm{TeV}(2 \times 2 \mathrm{TeV})$ collider plus parameters of lower energy machines (400 to $500 \mathrm{GeV}$ ) which may be developed as prototypes toward the high-energy goal.

Table 1: Parameter List for $\mu^{+}-\mu^{-}$colliders

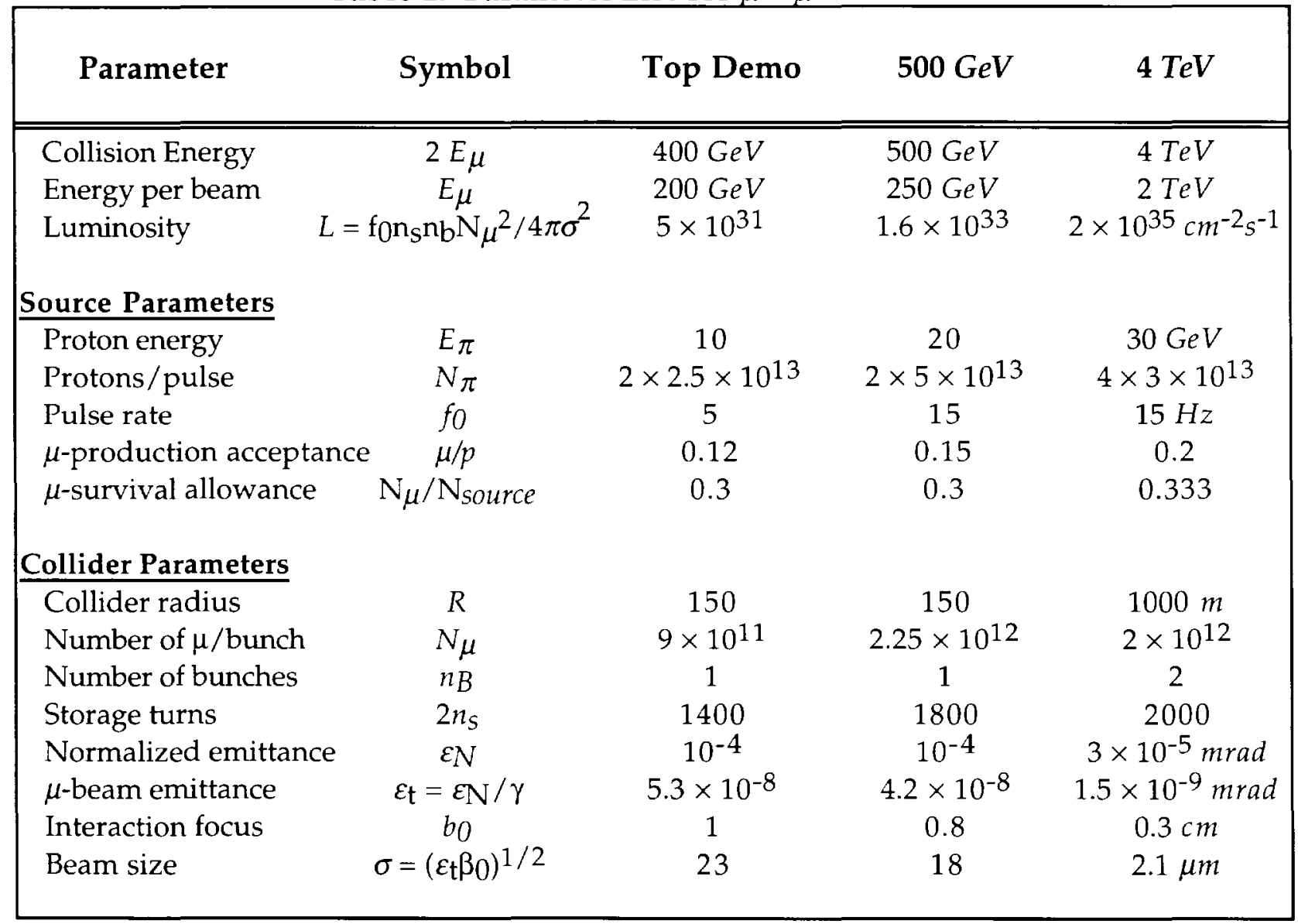




\section{Advantages of the Fermilab Site}

Fermilab has major advantages as a potential site for a $\mu^{+}-\mu^{-}$collider. A $\mu^{+}-\mu^{-}$collider facility would be a central part of the U.S. high energy physics program. Fermilab has had considerable experience in many of the various components and technologies which will be needed in a $\mu^{+}-\mu^{-}$ facility.

- Fermilab has a high intensity linac and rapid cycling synchrotron, ideal prototypes for the proton source.

- The $\bar{p}$ targetry and collection technology closely matches $\pi$-production technology.

- There is essential experience in Li lens technology (needed for $\pi$-production and $\mu$ cooling).

- The Fermilab neutrino and muon beam lines have given us experience in handling $\pi$-decay products.

- Fermilab experience in $r f$ and $S R F$ (superconducting RF) structures, from conventional 50 $M H z$ to $S R F 1.3 \mathrm{GHz}$, can be applied to the similar rf structures needed for $\mu^{+}-\mu^{-}$ acceleration.

- Fermilab experience in beam transport design and construction would be directly applicable to the beam transports of the $\mu^{+}-\mu^{-}$facility, including high-field superconducting magnets.

- There is a natural progression from a lower energy machine using existing or planned capabilities.

- The Fermilab site is matched to the size of a $\mu^{+}-\mu^{-}$complex; $\mu^{+}-\mu^{-}$colliders with up to $\sim 5$ $\mathrm{TeV}$ collision energies would fit entirely on the Fermilab site.

- The Fermilab site geology readily matches that needed for the new collider facility, with appropriate strata for placement of the accelerator and collider tunnels.

- The muon source, collection, cooling and low-energy accelerators would utilize and extend existing Fermilab facilities.

\section{Candidate for Site-Specific Layout}

In Fig. 2 we show an outline design for a 4 $\mathrm{TeV} \mu^{+}-\mu^{-}$Collider superimposed on the Fermilab site map.

Figure 2. A $4 \mathrm{TeV} \mathrm{cm}$ muon collider on the Fermilab site.

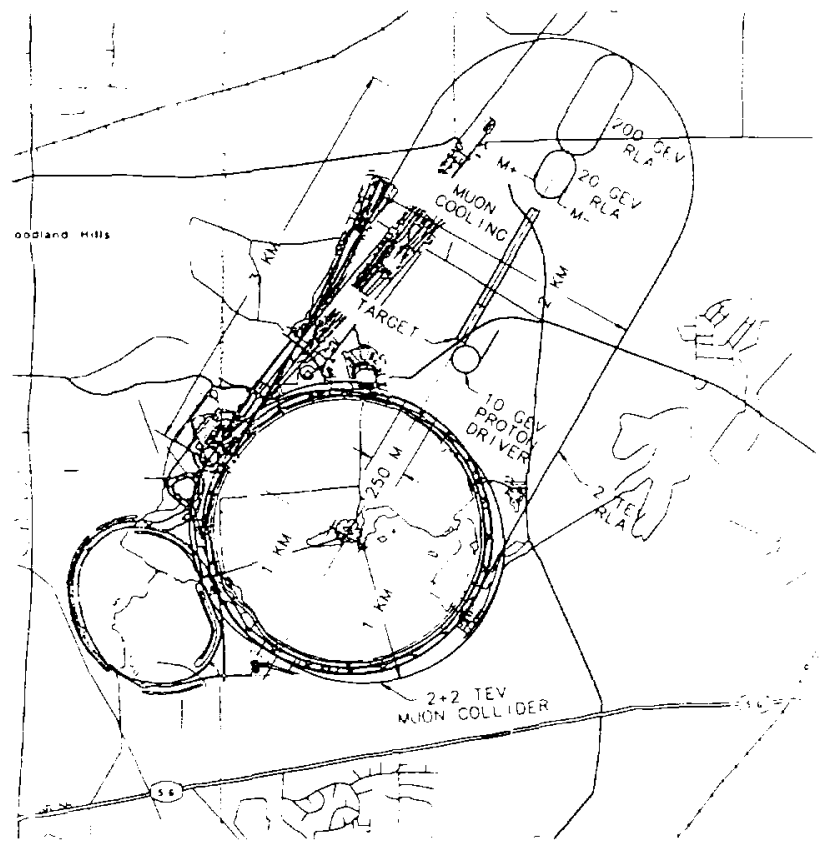


The collider facility consists of a proton source (10-30 GeV rapid-cycling proton synchrotron), high-intensity target, muon collection and cooling transport, followed by a linac and a sequence of recirculating linacs which take the beams from $\mathrm{GeV}$ energies to $2 \mathrm{TeV}$, and a collider ring with detector(s) for high-energy collisions. The machine footprint is set by the largest recirculating linac (a racetrack with $\sim 1 \mathrm{~km}$ radius arcs and $3 \mathrm{~km}$ linac straight sections). The Fermilab site is roughly a North-South-East-West square. We have chosen to place it along the Southwest-Northeast diagonal, since that maximizes the distances from the facility to off-site. (The location can be readjusted or even completely reoriented to meet other constraints.)

In this figure we have simply imposed a "site-independent" collider design on the Fermilab site map, and have not integrated in use of existing facilities. A Fermilab $\mu^{+}-\mu^{-}$Collider would likely use many existing Fermilab devices. The proton source could be an extension of the existing linac/booster complex, and that would fix its location. The $\pi$-production target and $\mu$ collection and cooling systems would then be located nearby and possibly use some of the existing antiproton or neutrino production lines and components, which have similar high-intensity targets. The $\mu$ linac and initial recirculating linac would also be nearby and therefore within the existing accelerator complex. The collider ring is similar in size to the existing Tevatron ring; however its detailed requirements are somewhat different and we assume a new ring with tunnel will be constructed.

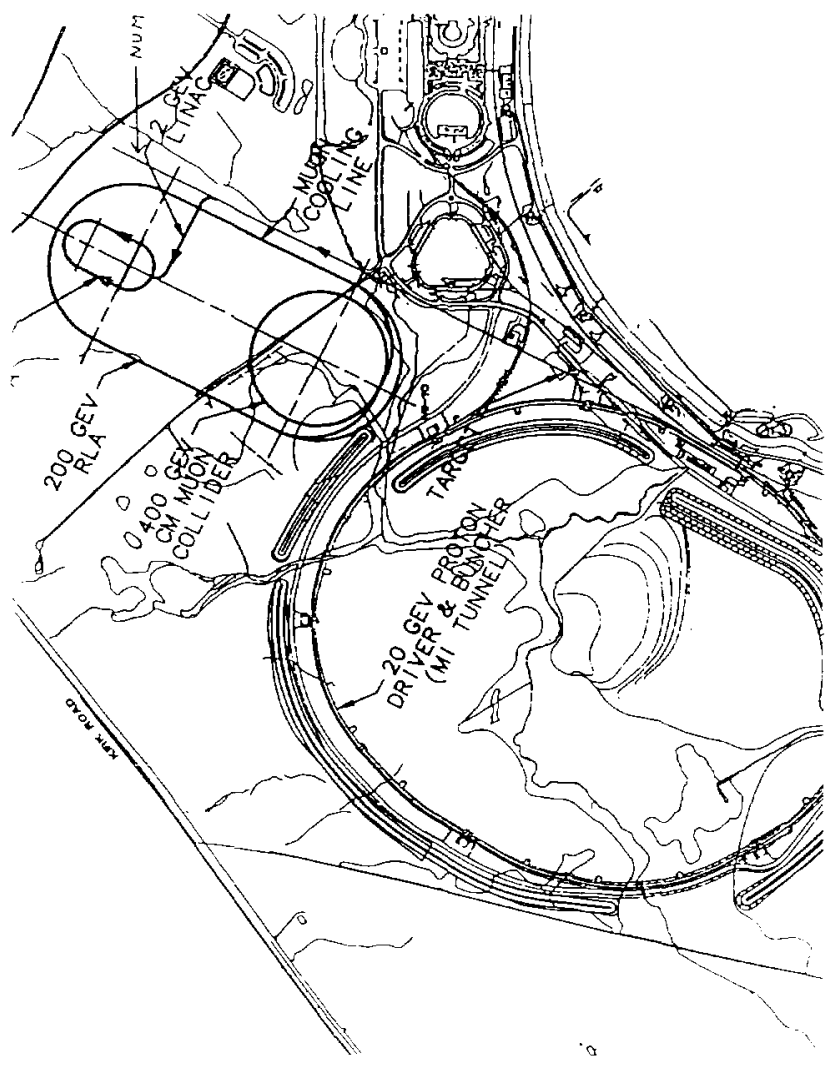

Figure 3. Muon collider layout utilizing portions of the Fermilab Accelerator complex.

In Fig. 3 we present a conceptual adaptation of the design to incorporate such use of existing facilities; the $\mu$ production and low-energy acceleration are concentrated near the existing complex. 
The muon source would begin with the existing Fermilab $400 \mathrm{MeV}$ proton linac (possibly extended to $1 \mathrm{GeV}$ ) feeding into the $8.9 \mathrm{GeV} / \mathrm{c}$ booster. Beam from the booster feeds into the Fermilab Main Injector which further accelerates the beam and bunches it into the short bunches needed for $\pi$-production. That beam is extracted and sent onto a high-intensity target with $\pi$ collection solenoid within the Fermilab NuMI target complex. The NuMI $\pi$ - decay line is used for the $\pi$-decay, $r$ rotation and $\mu$-beam cooling for both positive and negative $\mu$ 's. The full line is well-matched to the desired length, and the beam arrives at the desired elevation of the new tunnels for the subsequent linac and recirculating linac acceleration from 2 to 20 to 200 to $2000 \mathrm{GeV}$, after which it is injected into the $2 \mathrm{TeV} /$ beam collider ring.

Geological studies initiated for the Fermilab SSC site study indicate that there is a thick dolomite layer at a depth of $\sim 100 \mathrm{~m}$ beneath which is rather ideally suited for tunneling beam enclosures, both in the tunneling costs and stabilities and in ionizing beam energy loss handling. We would propose to place all of the new collider facility within this layer. This will minimize the surface disturbances.

\section{Prototype (demonstration) Machine}

Eventual development of a $4 \mathrm{TeV} \mu^{+}-\mu^{-}$Collider will probably require development of a prototype at lower energies. It would also be desirable for that prototype to include some new physics exploration. Such goals would be reached by a $400 \mathrm{GeV}$ Collider, with $200 \mathrm{GeV} \mu$-beams. Parameters are included in Table 1. The initial prototype would use the booster plus main injector to obtain compressed bunches of $\sim 10^{13}$ protons on target for a high-acceptance solenoidal line with If compression, cooling, and acceleration. The initial luminosity goal is $10^{31} \mathrm{~cm}^{-2} \mathrm{~s}^{-1}$. Upgrade of the proton source (with a super-booster and/or compressor ring) would enable a luminosity of $-5 \times 10^{31} \mathrm{~cm}^{-2} \mathrm{~s}^{-1}$. At this luminosity the $200 \times 200$ collider is suitable for studies of the top quark.

\section{Power Requirements}

While precise power requirements will depend upon a detailed design, some initial estimates may be made from the present conceptual development plus past accelerator experience. Extrapolating from $S R F$ experience, a $30 \%$ wall to beam power efficiency for the acceleration of $30 \mathrm{MW}$ of muons implies a need for $100 \mathrm{MW}$ of $\mathrm{r} f$ power. The proton source provides $3 \mathrm{MW}$ of beam power; from past experience this may require $\sim 30 \mathrm{MW}$ wall-plug power. Magnetic transport power requirements for the recirculating linacs would be similar to that for the Tevatron. The muon capture, cooling and compression system will also require $\sim 1 \mathrm{~km}$ of high-field magnets and $r f$, with possible wall-plug power needs of $\sim 20 \mathrm{MW}$. Totaling up the known requirements we obtain minimum wall-plug power requirements of the order of $200 \mathrm{MW}$. This is similar to but somewhat more than that installed Fermilab base of $150 \mathrm{MW}$. The requirements could increase if pulsed magnets rather than superconducting ones are used for muon transport. However this should not raise power over the $-300 \mathrm{MW}$ scale. These needs could be met by straightforward extension of existing capacity.

\section{Beam Handling and Radiation Protection}

With the parameters of Table 1 , the proton driver generates $\sim 3 M W$ of high-energy protons which are directed onto a high-intensity $\pi$-production target. This will require a tunnel with the production target, a $\pi$ collection and focusing system, a transport line for $\pi \rightarrow \mu$ decay, and a beam 
absorber. This is similar to the present $p$ production line, except the overall beam power is somewhat higher while the proton energy is somewhat lower. The design for this part of the $\mu+\mu-$ collider is a relatively straightforward extension of the $p$ source experience at Fermilab. In particular, the radiation protection considerations for the employees, public and environment are similar and would have similar solutions.

In addition, the collider facility will produce up to $\sim 30 \mathrm{MW}$ of $2 \mathrm{TeV}$ muons. The muons not used in the interaction regions will either decay within the collider ring or be sent to a beam absorber. Muon decay produces an electron plus two neutrinos of roughly equal energies. The electrons will deposit most of their energy in the walls of the magnets, which are designed to handle the resulting heat load. Muons that are not kept in the collider until decay would be extracted and sent to a beam absorber. The dimensions of the cylinder necessary to absorb the muons is about $2 \mathrm{~km}$ by $2 \mathrm{~m}$. Most likely this could be part of the dolomite in which the tunnel is located but if necessary could be a cylinder of concrete isolated from the environment. In either case the cylinder could lie entirely within the Fermilab site.

We must also consider the possibility of uncontrolled beam loss in an accelerator failure mode. While the average beam power is large, the actual beam energy within the beam pipe in any pulse is relatively small; up to $\sim 1.4 \mathrm{MJ}$. This is the largest beam energy that may be lost in a single accident. This is similar to the energy stored in the Tevatron, so similar constraints apply. If magnetic bending fields failed instantly, the $2 \mathrm{TeV}$ muons could exit the arcs, continuing in a straight line for the muon absorption length, about $2.5 \mathrm{~km}$. There are a few regions where a 2.5 $\mathrm{km}$ extension of the $\mu^{+}-\mu^{-}$transports would extend beyond the site boundaries. However, any such energy deposition would be confined deep beneath the ground within the impervious dolomite layer. Because the total energy deposited would be modest, any negative consequences to the environment or public are excluded.

The prototype $500 \mathrm{GeV}$ collider would produce $\sim 1 \mathrm{MW}$ of $250 \mathrm{GeV}$ muons. The beam energy range is $\sim 0.5 \mathrm{~km}$ and the collider could be arranged such that the $0.5 \mathrm{~km}$ range is entirely within the site boundaries. As with the 2 on $2 \mathrm{TeV}$ case a beam disposal line with $0.5 \mathrm{~km}$ range could be set up within the dolomite layer. 


\section{Chapter VI: Electron Colliders}

\section{Summary}

- Candidate sites for a linear $\mathrm{e}^{+} \mathrm{e}^{-}$collider have been identified, one with the interaction region on-site, one 20 miles to the West of Fermilab.

- A linear $\mathrm{e}^{+} \mathrm{e}^{-}$collider built at or near Fermilab would be largely underground and surface accesses would be minimized.

\section{Why Linear Colliders?}

Of the various new accelerator projects under consideration electron linear colliders of appropriate energy are nearest to realization. Significant $R \& D$ has gone on internationally both on the accelerators and on the physics potential. Fermilab has participated at a comparatively modest level in this R\&D at the FFTB at SLAC and at the TTF at DESY.

Table 1 lists the parameters of several designs.

Table 1 Parameters of various Linear Collider Designs for $500 \mathrm{GeV} \mathrm{Ecm}$

\begin{tabular}{|c|c|c|c|c|}
\hline & TESLA & SBLC & NLC & CLIC \\
\hline Total Length $(\mathrm{km})$ & 32 & 36 & 20 & 12 \\
\hline Operating frequency $(\mathrm{GHz})$ & 1.3 & 3 & 11.4 & 30 \\
\hline Field Gradient (MV/m) & 25 & 17 & 37 & 78 \\
\hline $\mathrm{P}(\mathrm{rf})$ peak/meter $(\mathrm{MW} / \mathrm{m})$ & 0.2 & 12.2 & 50 & 144 \\
\hline \# of Klystrons/P(klystron) (MW) & $604 / 8$ & $2452 / 150$ & $3940 / 50$ & - \\
\hline Pulse Length (m-sec) & 800 & 2.0 & 0.12 & 0.01 \\
\hline Nbunch/pulse & 1130 & 333 & 90 & 1 \\
\hline Bunch Spacing (n-sec) & 707 & 6 & 1.4 & - \\
\hline Rep. rate $(\mathrm{Hz})$ & 5 & 50 & 180 & 2500 \\
\hline Duty Cycle (\%) & 0.40 & 0.10 & 0.002 & - \\
\hline $\mathrm{Ne} /$ bunch $(\mathrm{e}+10)$ & 3.63 & 1.1 & 0.65 & 0.8 \\
\hline$g \varepsilon_{X} / \varepsilon_{y} \cdot(e-6 m)$ & $14 / 0.25$ & $5 / 0.25$ & $5 / 0.05$. & $2.5 / 0.15$ \\
\hline$\sigma_{x} / \sigma_{y}(\mathrm{e}-9 \mathrm{~m})$ & $846 / 19$ & $340 / 15$ & $320 / 3.2$ & $247 / 7.4$ \\
\hline$\sigma_{\mathrm{Z}}(\mathrm{e}-3 \mathrm{~m})$ & 0.7 & 0.3 & 0.1 & 0.2 \\
\hline$<\Delta \mathrm{E} / \mathrm{E}>(\%)$ & 2.9 & 3.0 & 2.4 & 3.5 \\
\hline Luminosity $\left(10^{* *} 33 \mathrm{~cm}-2 \mathrm{sec}-1\right)$ & 6 & 5 & 7.1 & 1.0 \\
\hline Pbeamtot (MW) & 16.5 & 14.5 & 8.4 & 1.6 \\
\hline Power Required (MW) & 88 & 136 & 103 & 100 \\
\hline
\end{tabular}

Siting a linear collider facility at Fermilab would necessarily involve going off-site, since none of the linear collider options would be contained within the Fermilab boundaries. We consider two sites for the linear collider option: one that contains the interaction region within Fermilab, but allows the tunnels and perhaps the damping rings to exist off-site. The second option provides for an entirely new facility off site, but within about a 30 minute drive of the existing Laboratory. Of 
the many linear collider designs $[1]$ we have chosen two (NLC and TESLA) as specific examples for siting.

\section{The Off-Site Facility}

A linear collider, since it is straight, can take advantage of existing easements for roadways, railways, and power lines. Because of the flat local terrain, many of these easements run in a straight line for $60 \mathrm{~km}$ or more. A representative site was chosen to illustrate this option. Running almost entirely from East to West along an existing power line easement, the site is completely straight. It also has good access from existing roadways, including an interstate highway. Because the facility lies beneath a power line, it should be relatively easy to provide the power needed by the collider. Acquisition of land off the easement would be required to provide areas for service halls and sufficient land easement for the damping rings.

Water cooling requirements for the facility could be met with a man-made aqueduct running the entire length of the collider. To provide sufficient cooling capacity, the aqueduct might be thirty feet wide by ten feet deep. The aqueduct would be filled entirely by capturing local rainfall and runoff. A study is needed to understand the impact on local water sources. An alternative to the aqueduct might be the location of fairly large lakes near the access points. These could be developed as part of local recreational facilities. In either case, work will be needed to develop a comprehensive water supply program that is mutually beneficial to the collider and local residents.

\section{The On-Site Detector Facility}

To take advantage of existing infrastructure, a representative site is under study that would place the intersecting regions on the Fermilab site. The orientation chosen, running almost entirely north to south, is optimized to limit interaction with local residential communities. The facilities would run under existing power line easements wherever possible. At first sight, the lines north of the Laboratory are not perfectly aligned with the lines to the south. Because of this the collider may have a horizontal kink at the IR, and it remains to be resolved whether a kink of sufficient size could be accommodated by the machine optics. The kink could be removed from this configuration with the consequence that land acquisition will have a greater impact on residents.

This siting would also favor placing the damping ring on the Fermilab site, and providing a long but low energy beam transport to the main linear colliders. The use of land off site may be problematic because of acquisition issues, although this siting goes through relatively sparsely populated regions. It is preferable to place as many facilities on the Fermilab site as possible.

Water cooling requirements for this site would be provided by existing cooling ponds, the addition of existing lakes into the cooling water system, and the construction of an additional cooling pond. In this sense the Fermilab site is ideal, because it contains sufficient land area to provide for water cooling by ponds for the linear collider facility. An initial study of water supply development on site is very promising.

\section{Tunnels and layout}

To take advantage of the excellent geology deep underground a linear electron collider at or near Fermilab would be built in a bored tunnel (perhaps using technologies discussed in Chapter IV) and the number of surface accesses and above ground buildings minimized. The current Tesla design is closer to those criteria than the current NLC design; however, there is nothing basic in the NLC design that excludes a similar approach. The details of the NLC design are given in the 
Snowmass '96 ZDR. [2] We will use as an example a Tesla design here. They differ in details but not at a level impacting choosing the Fermilab site or not.

Figure 1 shows a layout of Tesla and Figure 2 a cross section of the tunnel housing both the accelerating modules and their klystrons.

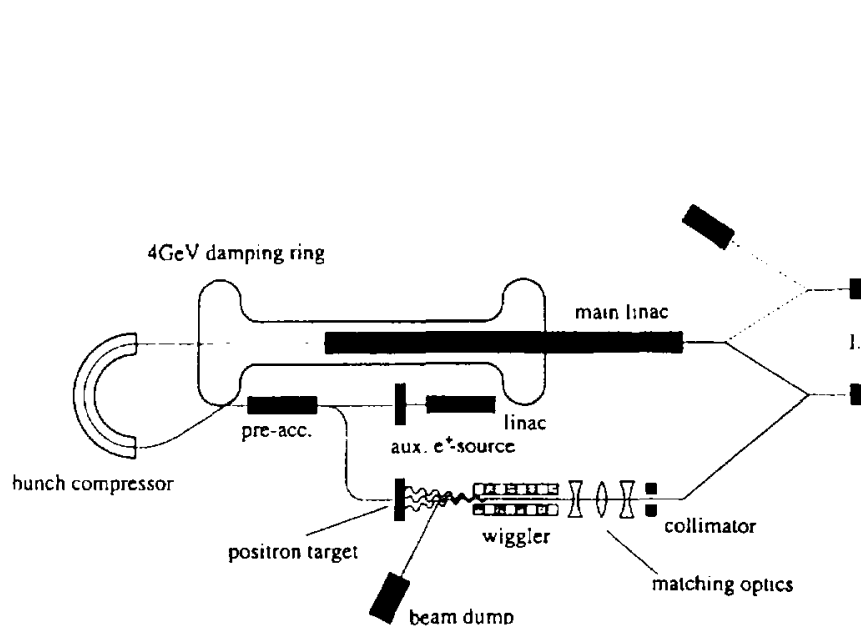

Figure 1. Tesla layout.

Figure 2. Tesla tunnel cross section.

The tunnel diameter is $4.9 \mathrm{~m}$ and houses the cavity modules, and the klystrons with their pulse transformers as well. Cryogenic modules are $1.2 \mathrm{~m}$ in diameter. Each $12 m$ module contains 8 one meter cavities fed by

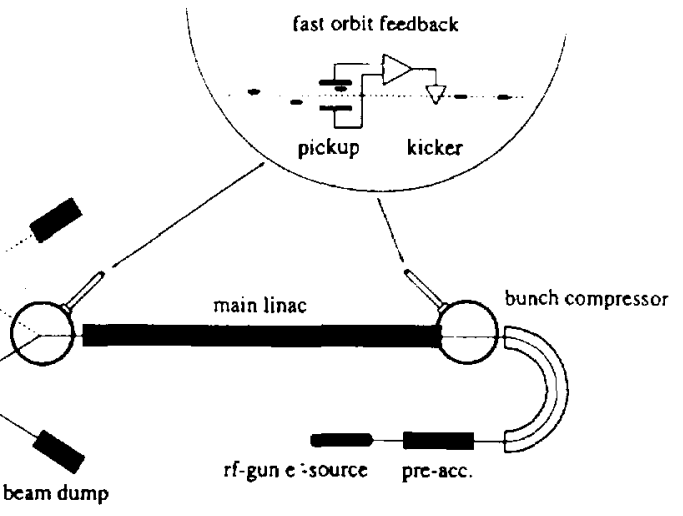
individual input power couplers. Quadrupole focusing magnets (along with beam steerers and position monitors) are included in modules as determined by the lattice at 25 to $50 \mathrm{~m}$ spacing.

The damping ring and/or low energy beam transport must be accommodated in the tunnel. The present plan is to place these overhead. They will need the standard complement of quadrupoles, steering, beam position detectors, vacuum, and diagnostics. However, these are low energy lines with simple and repetitive optics. This may be an application of permanent magnet technology, currently under development at Fermilab for the Recycler antiproton storage ring.

\section{Connections of Tesla with Fermilab}

A number of Fermilab people, mainly engineers, have been working on parts of the TTF over the past four years. Some of the connections between Fermilab people and Tesla are listed:

- The low temperature physics learned from the magnet effort has much in common with SRF. (superconducting RF)

- Cryogenic engineering is a major part of the Tesla design. Fermilab has designed and built major cryogenic components for TTF already and has interacted on both the cryomodule 
design and the overall Tesla cryoplant design. The cryomodules themselves look much like a magnet cryostat and use the same post supports.

- The RF modulator used for TTF is a direct descendant of the linac upgrade modulator. In the long run the RF power source is a major part and cost of the collider. The possibility of a SMES (superconducting magnetic energy storage) modulator has been proposed. Fermilab has the capability to evaluate and develop such a system.

- The input RF power coupler is a critical component closely associated with the cavity and its performance. Fermilab people have undertaken design and fabrication of the couplers and have gained significant experience with processing and testing of cavities at both Cornell and DESY.

\section{Tesla Damping Rings}

Two variants (at least) of damping rings are being considered. These need a large circumference because there are many bunches in a beam pulse and they must be injected into the linac one at a time. One design variation is Main Ring (or HERA) size and circular. The other is called a "dog bone" and has two long straight sections $(8 \mathrm{~km})$ with two loops at its ends of about $120 \mathrm{~m}$ diameter. This second type ring has its two long straight transports in the same tunnel as the linac.

Both of these options are of interest at Fermilab. The circular ring might be the Main Ring enclosure with the IP near by and the linacs going out in either direction. In this case low energy transports to carry the beams to the front of the linacs would be in the linac tunnels. If ground level Fermilab facilities were used, then the issue of relative elevation between these and the linac tunnel would need to be addressed.

\section{Site Considerations}

Typical tunnel depths appear to be 200-300 feet in order to get consistently into bed rock. To the west the Troy Bed Rock Valley may be a modest complication to construction past DeKalb. In general, the north south direction looks more favorable than east west. If tunnel in the drift made sense then probably terrain can be found where tunnel overburden could be kept to $100 \mathrm{ft}$ for a tunnel following earth's curvature. For Tesla the slope would need to be addressed in the cryogenic design.

Power lines running west just north of Route 30 look to be a very nice corridor and might make land easement easier. There are north south power lines to the east of DeKalb with what looks like easier access from I-88. The geology there might be interesting to look at. Just west of Rt. 47 probably has reasonable geology but no easy power corridor. From Fermilab north and south there is a good power corridor.

Just what sort of slow bends, (both horizontal and vertical) might be tolerated in the linac layout without special optical adaptation still needs to investigated. 


\section{REFERENCES}

\section{Reference for Chapter II: Geology and Hydrology}

1. Geological-Geotechnical Studies for Siting the Superconducting Super Collider in Illinois: Preliminary Geological Feasibility Report (1985). Illinois State Geological Survey, (EGN 111)

\section{References for Chapter IV: Large Hadron Colliders}

1. "Superferric magnets for $20 \mathrm{TeV}$," R. R. Wilson, Proceedings of the Snowmass 1982 Conference, page 330.

2. Proceedings of Workshop on Future Hadron Facilities in the U.S., Fermilab-TM-1907 (1994). see "Workshop Summary," S. D. Holmes, p.1, and "30 x 30 TeV-Summary Report," A. Chao, G. Dugan, M. Harrison, p.9.

3. "New Low-Cost Approaches to High Energy Hadron Colliders at Fermilab," compiled transparencies from the May 3, 1996 Mini-symposium at the APS Annual Meeting.

4. "Low-cost hadron colliders at Fermilab, A Discussion Paper," G. W. Foster and Ernest Malamud, TM-1976. A shorter version of this TM is Fermilab-Conf-96/145, "New Technologies for a Future Superconducting Proton Collider," presented at EIS '96, June 14, 1996.

5. http://www-ap.fnal.gov/PIPE/

6. "Microtunneling and horizontal directional drilling," Tom Iseley, Mini-Symposium, APS Annual Meeting, Indianapolis, May 3, 1996.

7. "Microtunneling database for the USA and Canada from 1984 to 1995," Alan Atalah and Paul Hadala, report from the Trenchless Technology Center, Louisiana Tech University.

8. "Visual Robotic Welding," Cary Kendziora and John Anderson. Private Communication, May, 1996.

\section{Reference for Chapter V: $\mu^{+} \mu^{-}$colliders}

1. " $\mu^{+} \mu^{-}$Collider, A Feasibility Study," The $\mu^{+} \mu^{-}$Collider Collaboration, issued simultaneously as BNL-52503, Fermilab-Conf-96/092, and LBNL-38946, July 1996.

\section{References for Chapter VI: $\mathrm{e}^{+} \mathrm{e}^{-}$colliders}

1. International Linear Collider Technical Review Committee Report, 1995, available from the SLAC Technical Publications Department as SLAC-R-95-471.

2. "Zeroth-order Design Report for the Next Linear Collider," The NLC Design Group, issued simultaneously as LBNL-PUB-5424, SLAC Report 474, and UCRL-ID-124161, May 1996. (2 volumes) 